\title{
USOS E ABUSOS DOS ESTUDOS DE CASO
}

\author{
ALDA JUDITH ALVES-MAZZOTTI \\ Programa de Pós-Graduação em Educação, Universidade Estácio de Sá - Rio de Janeiro \\ aldamazzotti@uol.com.br
}

\begin{abstract}
RESUMO
O artigo questiona duas tendências das pesquisas qualitativas rotuladas de "estudos de caso" no campo da educação: a primeira, considera qualquer investigação que focalize uma unidade um estudo de caso; a segunda supóe que, se o interesse pelo "caso" for devido à sua singularidade, não há como ou por que vinculá-lo à discussão corrente na área. Com o objetivo de contribuir para o enfrentamento desses problemas, o artigo busca examinar, na literatura sobre o tema, dois aspectos fundamentais para a discussão: a natureza dos estudos de caso e a questão da generalização ou da aplicabilidade do conhecimento, gerado por esse tipo de pesquisa, a outros contextos. Com base nas posições de dois dos mais reconhecidos especialistas em estudos de caso - Robert Yin e Robert Stake - são discutidos os critérios para avaliar se determinada pesquisa pode ou não ser classificada como um estudo de caso, bem como as alternativas à generalização de tipo estatístico oferecidas por aqueles autores. ESTUDO DE CASO - YIN, ROBERT - STAKE, ROBERT - PESQUISA EDUCACIONAL
\end{abstract}

\section{ABSTRACT}

USES AND ABUSES OF CASE STUDIES. The article questions two tendencies present in a great part of the qualitative investigations labeled "case studies" in the field of education: the first considers that any enquiry that focus on just one unity is a case study; the second supposes that, since the interest in the "case" is due to its uniqueness, there is no need or way of relating it to the current discussion in the area. With the objective of contributing to deal with these problems, the article tries to examine, in the available literature, two essential aspects of the proposed discussion: a) the nature of case studies; b) the issue of generalization of the knowledge generated by that type of research to other contexts. Based on the positions of two of the most prestigious specialists in case studies - Robert Yin e Robert Stake - criteria to evaluate if a given study can or cannot be classified as a case study are discussed. Also, alternatives to statistical generalization offered by those authors are given.

CASE STUDY - YIN, ROBERT - STAKE, ROBERT - EDUCATIONAL RESEARCH 
O processo de produção do conhecimento científico pode ser visto como uma espécie de conversa, uma interlocução contínua entre pesquisadores de uma dada área. Participar desse diálogo é essencial ao ofício de pesquisador, pois é por meio dele, da avaliação crítica da comunidade acadêmica, que os novos conhecimentos produzidos são validados ou não. Daí a importância atribuída à divulgação da produção científica em livros, periódicos ou eventos, bem como à clareza do discurso que a expõe, uma vez que essas constituem condições necessárias à crítica dos pares. Sobre a questão, Moroz e Gianfaldoni são taxativas:

...só é possível dizer que um conhecimento foi produzido, uma vez que foi tornado público. [...] só quando discutido com outros colegas, quando alvo de debates, é que o conhecimento poderá contribuir para o desenvolvimento de uma área específica da ciência. É passando pela comunicação que um trabalho, uma explicação e uma teoria poderão ser aceitos ou rejeitados. (2002, p. I I)

A validação do conhecimento pelos pares assumiu ainda maior importância após a derrocada de dois pilares do positivismo: o primado do método como garantia do rigor, que Adorno (1983, p.219) chama "obsessão metodológica"; e a crença na objetividade e racionalidade da ciência, abalada pela revolução provocada por Kuhn (1970). De fato, a visão de uma ciência objetiva e neutra, capaz de formular leis gerais cujo valor de verdade seria garantido pela aplicação criteriosa do método já não se sustenta (Alves-Mazzotti; Gewandsznajder, 2004). Hoje, a maioria dos cientistas admite que nenhum conhecimento é inteiramente objetivo e que os valores e crenças do pesquisador podem interferir no seu trabalho e, nesse caso, a única objetividade a que podemos aspirar é aquela que resulta da exposição de nossas pesquisas à crítica da comunidade científica (Popper, 1978). Por ser intersubjetivo, esse processo permite identificar os vieses do pesquisador, decorrentes das crenças e valores associados à sua inserção social e à sua história.

Assim, a validação do conhecimento gerado pela pesquisa, a aprovação de sua confiabilidade e relevância pela comunidade acadêmica, exige que o pesquisador se mostre familiarizado com o estado atual do conhecimento sobre a temática focalizada, de modo que ele possa, de alguma forma, inserir sua pesquisa no processo de produção coletiva do conhecimento. Tal preocupa- 
ção favorece o diálogo com aqueles que se interessam pela mesma temática, além de permitir a cumulatividade e aplicabilidade dos resultados.

No entanto, temos observado que muitas pesquisas classificadas por seus autores como "estudos de caso" parecem desconsiderar o fato de que o conhecimento científico desenvolve-se por meio desse processo de construção coletiva. Ao não situar seu estudo na discussão acadêmica mais ampla, o pesquisador reduz a questão estudada ao recorte de sua própria pesquisa, restringindo a possibilidade de aplicação de suas conclusões a outros contextos pouco contribuindo para o avanço do conhecimento e a construção de teorias. Tal atitude freqüentemente resulta em estudos que só têm interesse para os que dele participaram, ficando à margem do debate acadêmico. Esse problema não é novo nem se restringe aos estudos de caso, mas, sem dúvida, é mais freqüente nesse tipo de pesquisa. Talvez por focalizar apenas a unidade ou por enfatizar o interesse intrínseco pelo "caso" pelo que ele tem de singular, muitos pesquisadores tendem a tratá-lo como algo à parte, tanto em sua gênese, apresentando-o de modo desconectado da discussão corrente na área, como em seu desenvolvimento, no qual não se observa qualquer preocupação com o processo de construção coletiva do conhecimento.

$\mathrm{Na}$ verdade, o maior problema de grande parte dos trabalhos apresentados como estudos de caso é que eles não se caracterizam como tal. Refletindo uma visão equivocada sobre a natureza desse tipo de pesquisa, esses estudos são assim chamados por seus autores pelo simples fato de serem desenvolvidos em apenas uma unidade (uma escola, uma turma) ou por incluírem um número muito reduzido de sujeitos. Freqüentemente, o autor apenas aplica um questionário ou faz entrevistas em uma escola, sem explicitar por que aquela escola e não outra, deixando a impressão de que poderia ser qualquer uma. Ou seja, a escola ou a turma escolhida não é um "caso", não apresenta qualquer interesse em si, é apenas um local disponível para a coleta de dados. Em conseqüência, a interpretação desses dados é superficial, sem recurso ao contexto e à história.

Os problemas mencionados parecem ser, em parte, induzidos por equívocos da literatura sobre o tema, bem como por discordâncias entre os autores que dele se ocupam. Talvez o maior desses equívocos resida na afirmação de que os estudos de caso são um tipo de pesquisa mais fácil, pelo fato de lidar com uma ou poucas unidades. Essa idéia foi disseminada por Bogdan e 
Biklen ( 1994, p.89)', que sugerem que investigadores iniciantes comecem sua aprendizagem de pesquisa por meio de estudos de caso por "serem mais fáceis de realizar". Tal afirmação escamoteia a complexidade desse tipo de pesquisa, bem como as dificuldades que the são inerentes.

Examinaremos, a seguir, dois aspectos fundamentais para a compreensão das dificuldades aqui apontadas: a caracterização dos estudos de caso qualitativos e a questão da generalização ou aplicabilidade em outros contextos de conhecimento produzido por esse tipo de pesquisa. Para isso, serão confrontados dois autores, os quais foram selecionados por serem referência obrigatória no que se refere aos estudos de caso e por operarem em paradigmas diferentes: Robert Stake, mais afinado com o construcionismo social, e Robert Yin, com o pós-positivismo. Procuraremos demonstrar que, apesar de apresentarem algumas diferenças irreconciliáveis, vinculadas aos paradigmas nos quais operam, esses autores estão de acordo sobre algumas questões essenciais.

\section{CARACTERIZAÇÃO}

Uma dificuldade inicial para a caracterização dos estudos de caso reside no fato de que adotam diferentes metodologias e são usados não apenas como modalidade de pesquisa, mas também para fins de ensino e consultoria, com o objetivo de ilustrar uma argumentação, uma categoria ou uma condição. Além disso, seu uso se estende a diversas áreas de conhecimento, como a Psicologia, a Psicanálise, a Sociologia, a Ciência Política, o Direito, a Administração, entre outras. Neste artigo tratamos apenas de estudos de caso qualitativos usados como modalidade de pesquisa.

Os estudos de caso mais comuns são os que focalizam apenas uma unidade: um indivíduo (como os "casos clínicos" descritos por Freud), um pequeno grupo (como o estudo de Paul Willis sobre um grupo de rapazes da classe trabalhadora inglesa), uma instituição (como uma escola, um hospital), um programa (como o Bolsa Família), ou um evento (a eleição do diretor de uma escola). Podemos ter também estudos de casos múltiplos, nos quais vários estu-

1. Um dos livros de metodologia mais usados por professores e alunos de pós-graduação. 
dos são conduzidos simultaneamente: vários indivíduos (como, por exemplo, professores alfabetizadores bem-sucedidos), várias instituições (diferentes escolas que estão desenvolvendo um mesmo projeto), por exemplo.

Para Stake (2000, p.436), o estudo de caso como estratégia de pesquisa caracteriza-se justamente por esse interesse em casos individuais e não pelos métodos de investigação, os quais podem ser os mais variados, tanto qualitativos como quantitativos. Mas, o autor alerta para o fato de que "nem tudo pode ser considerado um caso" e oferece algumas pistas para a identificação do que pode constituir um caso. Para ele, um caso é uma unidade específica, um sistema delimitado cujas partes são integradas. Assim, por exemplo, o comportamento de uma criança apresenta padrões nos quais atuam fatores fisiológicos, psicológicos, culturais, entre outros. Algumas características podem estar dentro do sistema, nos limites do caso, e outras fora, e nem sempre é fácil para o pesquisador dizer onde termina o indivíduo e começa o contexto. Da mesma maneira, uma escola, como caso, deve ser estudada como um sistema delimitado, embora a influência de diferentes aspectos que se ligam a esse sistema, como o contexto físico, sociocultural, histórico e econômico em que está inserida a escola, as normas da Secretaria de Educação etc., não deva ser ignorada.

Stake distingue três tipos de estudos de caso a partir de suas finalidades: intrínseco, instrumental e coletivo. No estudo de caso intrínseco busca-se melhor compreensão de um caso apenas pelo interesse despertado por aquele caso particular. Nas palavras do próprio autor:

Aqui, o estudo não é empreendido primariamente porque o caso representa outros casos ou porque ilustra um traço ou problema particular, mas porque, em todas as suas particularidades e no que têm de comum, este caso é de interesse em si. O pesquisador, pelo menos temporariamente, subordina outras curiosidades para que as histórias dos que "vivem o caso" emerjam. O objetivo não é vir a entender algum constructo abstrato ou fenômeno genérico, tal como letramento, ou uso de droga por adolescentes ou o que um diretor de escola faz. O objetivo não é construir teoria - embora em outras vezes o pesquisador possa fazer exatamente isto. (Stake, 2000, p.437, tradução nossa)

No estudo de caso instrumental, ao contrário, o interesse no caso devese à crença de que ele poderá facilitar a compreensão de algo mais amplo, uma 
vez que pode servir para fornecer insights sobre um assunto ou para contestar uma generalização amplamente aceita, apresentando um caso que nela não se encaixa.

No estudo de caso coletivo o pesquisador estuda conjuntamente alguns casos para investigar um dado fenômeno, podendo ser visto como um estudo instrumental estendido a vários casos. Os casos individuais que se incluem no conjunto estudado podem ou não ser selecionados por manifestar alguma característica comum. Eles são escolhidos porque se acredita que seu estudo permitirá melhor compreensão, ou mesmo melhor teorização, sobre um conjunto ainda maior de casos.

Podemos concluir, portanto, que os estudos de caso instrumentais, coletivos ou não, pretendem favorecer ou, ao contrário, contestar uma generalização aceita, enquanto os estudos intrínsecos, em princípio, não se preocupam com isso. Stake considera que o importante é otimizar a compreensão do caso ao invés de privilegiar a generalização para além do caso. Aqui, a posição do autor é aparentemente contrária à que defendemos e a ela voltaremos na seção em que discutiremos a generalização.

Cabe esclarecer que o objetivo de Stake, ao categorizar os estudos de caso, não é taxionômico e sim o de enfatizar a variedade de preocupações e orientações metodológicas relacionadas aos estudos de caso, mesmo porque admite que os estudos freqüentemente não encaixam claramente naquelas categorias. Para ele, os pesquisadores de caso buscam tanto o que é comum quanto o que é particular em cada caso, mas o resultado final geralmente retrata algo de original em decorrência de um ou mais dos seguintes aspectos:
a. a natureza do caso;
b. o histórico do caso;
c. o contexto (físico, econômico, político, legal, estético etc.);
d. outros casos pelos quais é reconhecido;
e. os informantes pelos quais pode ser conhecido.

Stake acrescenta que, para mostrar a peculiaridade do caso, os pesquisadores freqüentemente reúnem dados sobre todos os aspectos citados.

Finalmente, um último aspecto importante para a caracterização do estudo de caso é o tipo de questões pertinentes a esse gênero de pesquisa. Stake 
indica que, como qualquer pesquisa, o estudo de caso é geralmente organizado em torno de um pequeno número de questões. Mas, esclarece que nessa modalidade de investigação predominam questões ou temáticas sobre relações complexas, situadas e problemáticas.

Yin (1984) também enfatiza a importância do tipo de questões propostas para distinguir os estudos de caso de outras modalidades de pesquisa nas ciências sociais. Afirma que a estratégia é geralmente usada quando as questões de interesse do estudo referem-se ao como e ao porquê; quando o pesquisador tem pouco controle sobre os acontecimentos; e quando o foco se dirige a um fenômeno contemporâneo em um contexto natural.

Ao compararmos o que dizem os dois autores sobre as características de questões típicas dos estudos de caso, percebemos que são bastante semelhantes: questões sobre o como e o porquê se referem a relações complexas, sobre as quais o pesquisador tem pouco controle; são referidas a um dado contexto, portanto, situadas. De maneira sintética, Yin define o estudo de caso como

...uma pesquisa empírica que investiga um fenômeno contemporâneo em seu contexto natural, em situações em que as fronteiras entre o contexto e o fenômeno não são claramente evidentes, utilizando múltiplas fontes de evidência. ( 1984, p.23, tradução nossa)

Ao definir o objeto do estudo de caso como um fenômeno contemporâneo, o autor procura distingui-lo dos estudos históricos, nos quais a evolução temporal é o foco de interesse, o que não significa que nos estudos de caso não se recorra a fatos passados para compreender o presente. Entretanto, a distinção proposta não é unanimemente aceita. Bogdan e Biklen (1 994, p.90 e 92), por exemplo, citam, entre as diferentes modalidades de estudos de caso, o que chamam de "estudos de caso de organização numa perspectiva histórica" e as "histórias de vida".

Yin descreve três situações nas quais o estudo de caso é indicado. A primeira ocorre quando o caso em pauta é crítico para testar uma hipótese ou teoria previamente explicitada. $\bigcirc$ autor cita como exemplo uma pesquisa em que Gross e outros pesquisadores testaram a proposição teórica, amplamente aceita, segundo a qual o fracasso na implementação de inovações se deve a barreiras postas pelas organizações. Para atender a esse objetivo tais pesquisadores selecionaram 
uma escola que tinha uma história de abertura às inovações e mostraram que, nessa escola, uma inovação fracassou, não pela existência de barreiras, mas por falhas no processo de implementação. Esse resultado, embora restrito a um único caso, modificou a teoria da inovação, redirecionando o foco das investigações da identificação de barreiras à preocupação com o processo de implementação.

A segunda razão que justifica a opção por um estudo de caso é o fato de ele ser extremo ou único. Essa é a situação, comum em Psicologia Clínica, na qual uma pessoa, devido a uma deficiência ou a condições de vida não usuais, apresenta um padrão de comportamento extremamente raro e para o qual não existem ainda teorias explicativas convincentes. $\bigcirc$ fato de que tais situações são instigantes e extremamente raras justifica a análise em profundidade de qualquer caso em que ocorram tais padrões de comportamento. Como exemplo de estudos desse tipo, poderíamos citar os relatos sobre drásticas mudanças de comportamento em pacientes com comprometimento de diferentes áreas cerebrais e sobre crianças criadas sem contato humano.

A terceira situação descrita por Yin é o caso revelador, que ocorre quando o pesquisador tem acesso a uma situação ou fenômeno até então inacessível à investigação científica. Poderíamos imaginar, como exemplo desse tipo de investigação, a possibilidade de um pesquisador que desenvolva ação comunitária em uma favela dominada pelo tráfico de drogas, observar as relações que as crianças que trabalham para os traficantes mantém com suas famílias, com seus professores ou com as demais crianças da favela.

Yin acrescenta, ainda, que estudos de caso são também usados como etapas exploratórias na pesquisa de fenômenos pouco investigados ou como estudos-piloto para orientar o design de estudos de casos múltiplos. Note-se que, aqui, aparece um outro critério que justifica a escolha do estudo de caso como abordagem adequada de um problema de pesquisa: tratar-se de fenômeno pouco investigado, o qual exige estudo aprofundado de poucos casos, que leve à identificação de categorias de observação ou à geração de hipóteses para estudos posteriores.

Comparando os tipos descritos pelos autores focalizados, podemos observar que o estudo de caso exploratório, assim como o que Yin denomina de crítico, são formas de estudo de caso instrumental na nomenclatura de Stake, enquanto o estudo de caso extremo e o revelador se aproximariam do tipo intrínseco na classificação de Stake. 
A descrição desses tipos oferece pistas importantes para que se possa avaliar se uma dada investigação pode ser classificada como um estudo de caso. Usando um critério mais geral, Yin (1984, p. I4) afirma que uma investigação caracteriza-se como um estudo de caso se "surge do desejo de compreender fenômenos sociais complexos" e "retém as características significativas e holísticas de eventos da vida real".

Após oferecer orientações sobre o planejamento, a coleta e análise dos dados e a organização do relatório, Yin conclui com a seguinte indagação: "o que faz um estudo de caso exemplar?". O autor admite que a pergunta é de difícil resposta, pois não basta seguir à risca os procedimentos indicados para que se tenha um caso exemplar, que seja capaz de oferecer insights referentes a processos individuais ou sociais. Mas, se arrisca a propor as seguintes características consideradas essenciais a um estudo de caso exemplar:

- $\bigcirc$ caso deve ser completo. Três indicadores de completude são apontados: as fronteiras do caso, isto é, a distinção entre o fenômeno que está sendo estudado e seu contexto, são objeto de atenção; a narrativa demonstra, de modo convincente, que houve "um esforço exaustivo" (Yin, 1984, p. I42) para coletar as evidências relevantes; e o estudo é planejado de tal maneira que sua finalização não é determinada por limites de tempo ou de recursos.

- O caso deve considerar perspectivas ou hipóteses alternativas. $\bigcirc$ pesquisador deve buscar explicações ou perspectivas rivais daquelas adotadas no estudo e examinar as evidências de acordo com essas perspectivas.

- As evidências devem ser suficientemente poderosas para sustentar as conclusões e ganhar a confiança do leitor quanto à seriedade do trabalho realizado.

- O relato do estudo deve ser atraente. Isso significa que deve ser escrito de maneira clara e instigante, "seduzindo" o leitor, de modo a que este permaneça "ligado" na narrativa até o final.

Essas características, Yin nos informa, não refletem apenas a opinião dele. Em uma investigação anterior foi solicitado a 21 prestigiados cientistas sociais que apontassem as qualidades que consideravam mais importantes em um estudo de caso. As características aqui apresentadas condensam aqueles resultados. 


\section{GENERALIZAÇÃO E APLICABILIDADE DOS RESULTADOS}

A afirmação de que os estudos de caso oferecem pouca base para generalização é, segundo Yin ( 1984, p.48-49), uma das facetas dos preconceitos que cercam esta estratégia de pesquisa. $\bigcirc$ autor argumenta que, se não se pode generalizar a partir de um único caso, também não se pode generalizar com base em um único experimento. De fato, as generalizações são usualmente baseadas em um conjunto de experimentos replicando o mesmo esquema em diferentes condições. Para Yin, o mesmo raciocínio pode ser usado para os estudos de casos múltiplos e, nesse sentido, a lógica que rege o desenho da pesquisa não é a da amostragem, mas a da replicação. Assim, cada caso deve ser selecionado de acordo com uma das seguintes previsões: ou se espera encontrar resultados semelhantes nas diversas unidades investigadas (replicação propriamente dita) ou se espera resultados diferentes em razão de fatores previamente antecipados pelo pesquisador ("replicação teórica"). Tal como os experimentos, os estudos de caso, portanto, não representam "amostra" cujos resultados seriam generalizáveis para uma população (generalização estatística), o pesquisador não procura casos representativos de uma população para a qual pretende generalizar os resultados, mas a partir de um conjunto particular de resultados, ele pode gerar proposições teóricas que seriam aplicáveis a outros contextos. A isto Yin (1 984, p.39) denomina "generalização analítica".

Yin exemplifica essa noção com um estudo de caso conduzido por Jane Jacobs (2000) intitulado Morte e vida de grandes cidades. Embora a pesquisa focalize a cidade de Nova York, a autora parte dos dados obtidos nesse contexto para discutir aspectos teóricos mais amplos, como o papel das calçadas e dos parques, a necessidade de quarteirões pequenos, os processos de favelização e desfavelização, chegando à construção de uma teoria sobre planejamento urbano que pode ser aplicada a outras grandes cidades. A partir dessa teoria, novos estudos empíricos foram feitos examinando uma ou outra de suas proposições, pode-se dizer que aquele estudo inicial é, até hoje, considerado uma significativa contribuição para a área de planejamento urbano.

Já Stake assume uma posição distinta sobre a generalização. Critica o fato de que mesmo metodólogos "qualitativos" como Yin fazem restrições ao estudo do particular, como se o estudo intrínseco de um caso não fosse tão importante quanto estudos para obter generalizações relativas a uma multiplici- 
dade de casos. Essa perspectiva levaria, segundo o autor, a privilegiar três tipos de estudos de caso: os apresentados como típicos de outros casos; os exploratórios, que levam a novos estudos que permitam a generalização; ou os que constituiriam um primeiro passo na construção de uma teoria. No entender de Stake, essa preocupação com a generalização compete com a busca da particularidade, e não deveria ser enfatizada em toda pesquisa. Observa que se, por um lado, os trabalhos sobre a metodologia dos estudos de caso são escritos essencialmente por especialistas, convencidos que a pesquisa científica deve contribuir para a generalização, a maior parte dos estudos é conduzida por pesquisadores interessados no aspecto intrínseco do caso estudado e demonstram pouca preocupação com o avanço da ciência. Seus designs visam à compreensão do que é importante naquele caso, e para isso propõem as questões que lhes parecem relevantes, descrevem contextos e fazem interpretações próprias ao caso, proporcionando ao leitor "descrição densa".

Os métodos de estudo de caso instrumental, por sua vez, levam o estudioso a indicar de que maneira as preocupações de pesquisadores e teóricos relacionados ao tema focalizado se apresentam no caso estudado. Considerando que, nesse caso, as questões críticas são geralmente conhecidas a priori, tal projeto pode levar vantagem em relação aos demais, por contar com instrumentos já desenvolvidos e esquemas de codificação preconcebidos.

No entanto, Stake admite que, mesmo no estudo intrínseco, os pesquisadores não evitam a generalização, freqüentemente antecipando acontecimentos esperados em seus casos e em outras situações. $O$ pesquisador busca apreender o suficiente sobre o caso estudado de modo a expressar significados complexos em uma narrativa suficientemente descritiva para que os leitores possam, de modo vicário, experienciar as situações e chegar a conclusões (mesmo que essas sejam diferentes das do pesquisador). Assim, mesmo um estudo de caso intrínseco pode ser visto como um passo em direção à generalização. Para o autor, os problemas ocorrem quando o compromisso com a generalização ou com a teorização é tão grande que a atenção do pesquisador é desviada de características importantes para a compreensão do caso em si. Com sua própria história, única, o caso é uma entidade complexa operando dentro de vários contextos - físico, econômico, ético, estético e outros. O caso é singular, mas tem subunidades, diferentes grupos, situações, enfim, uma concatenação de domínios que não são apreendidos com facilidade. A compreensão holística do caso exige o exame dessas complexidades. 
Stake chega, então, à questão central no que se refere à generalização. O que se pode aprender de um único caso? Para ele, o que aprendemos com um caso singular relaciona-se ao fato de que o caso é semelhante ou diferente de outros casos conhecidos. Pesquisadores naturalísticos, etnográficos e fenomenológicos relatam seus casos sabendo que eles serão comparados a outros e, por isso, buscam descrevê-los detalhadamente para que o leitor possa fazer boas comparações. Por meio de uma narrativa densa e viva, o pesquisador pode oferecer oportunidade para a experiência vicária, isto é, pode levar os leitores a associarem o que foi observado naquele caso a acontecimentos vividos por eles próprios em outros contextos. Esse processo corresponde ao que Stake denominou "generalização naturalística", conceito introduzido em artigo publicado em 1978, como uma alternativa à generalização baseada em amostras consideradas representativas de uma população.

\section{CONSIDERAÇÕES FINAIS}

A partir de uma analogia entre o processo de produção do conhecimento científico e uma conversação entre pares, verificou-se que muitos estudos de caso parecem monólogos: não se inserem no fluxo de discussão anterior nem dão margem a que se dê continuidade à conversa, incorporando suas possíveis contribuições. Além disso, demonstrou-se preocupação com a qualidade dessas pesquisas, muitas das quais parecem desconhecer a natureza e a complexidade dos estudos de caso. Buscou-se examinar, na literatura sobre o tema, dois aspectos fundamentais para a discussão dos principais problemas apontados nas pesquisas, em particular as desenvolvidas por pesquisadores iniciantes: a caracterização dos estudos de caso e a questão da generalização, focalizando a posição de dois reconhecidos especialistas em estudos de caso: Robert Yin e Robert Stake.

Cabe, inicialmente, enfatizar que os dois autores analisados estão claramente de acordo em dois pontos, apontados no início deste artigo, como essenciais à compreensão dos estudos de caso: nem todo estudo de uma única unidade pode ser considerado um estudo de caso, e estudos de caso não são fáceis de ser realizados, ao contrário, eles se revestem de grande complexidade, o que exige o recurso a técnicas variadas de coleta de dados.

Verificou-se porém, que há divergências entre aqueles autores, tanto no que se refere à caracterização dos estudos de caso quanto à questão da gene- 
ralização, divergências essas claramente vinculadas aos pressupostos dos paradigmas com os quais cada um deles se identifica.

Resta, agora, relacionar as concepções de Stake e Yin sobre os estudos de caso ao diálogo com os pares, para a validação do trabalho científico. É necessário, primeiramente, saber como avaliar se uma pesquisa efetivamente se caracteriza como estudo de caso. Vale lembrar que Yin descreve três tipos que podem ser tomados como critérios para avaliar se uma dada investigação pode ou não ser classificada como um estudo de caso: o caso deve ser crítico, extremo ou único ou, então, revelador; e, em qualquer dessas situações, deve focalizar fenômenos sociais complexos, retendo as características holísticas dos eventos da vida real. Yin descreve, ainda, um outro critério, referente aos estudos de tipo exploratório: eles devem aprofundar a compreensão de um fenômeno pouco investigado, levando à identificação de categorias de observação ou à geração de hipóteses para estudos posteriores. Em Stake, podem ser encontrados dois critérios essenciais para definir um estudo de caso: é uma investigação que focaliza um fenômeno original, tratando-o como um sistema delimitado cujas partes são integradas.

O exame das concepções desses dois autores indica, portanto, que ambos têm, subjacentes às suas concepções, critérios para a seleção e o desenvolvimento de estudos de caso. Mas mostra também que a inserção do problema na discussão travada na área de conhecimento é necessária em qualquer dos tipos de estudo de caso descritos. Mais especificamente, não há como mostrar porque um caso é crítico, extremo ou único, revelador ou, ainda, exploratório (Yin), instrumental ou, mesmo intrínseco (Stake), sem analisar a produção acumulada na área. Como lembra Stake (2000), os pesquisadores sempre buscam tanto o que é comum quanto o que é particular em cada caso e, para isso, é preciso estar a par da discussão corrente.

Quanto à possibilidade de generalização a partir dos estudos de caso, mostrou-se que Yin considera que é sempre possível gerar hipóteses que possam ser testadas em outros contextos (replicação) e, caso sejam reiteradamente confirmadas, podem ser generalizadas para contextos similares ("generalização analítica"). Já Stake (2000, p.439) afirma que a generalização não deveria ser uma exigência feita a todo e qualquer estudo, pois essa preocupação, caso seja excessiva, pode desviar a atenção do pesquisador de características importantes para a compreensão do caso em si. Admite, porém, que "mesmo um es- 
tudo de caso intrínseco pode ser visto como um pequeno passo em direção a uma grande generalização". O que Stake (1978) introduz, ao propor sua "generalização naturalística", é uma mudança de perspectiva: sugere que ao invés de assumir a responsabilidade de definir para que populações e/ou contextos os resultados obtidos podem ser generalizados, o pesquisador deixe essa decisão para o leitor. Este, ao se deparar com a descrição detalhada dos sujeitos, das relações que mantêm entre si, de seus comportamentos e das situações em que ocorrem, enfim, com uma "descrição densa" do caso, decidirá se as interpretações, hipóteses, insights apresentados naquele estudo podem ser aplicados ao caso de seu interesse.

$\mathrm{Na}$ verdade, o que tanto Yin quanto Stake negam é que, com base nos estudos de caso, seja possível fazer generalizações de tipo estatístico. Mas, nenhum dos dois desconhece a importância de se ir além do caso, tanto que cada um deles propõe uma forma alternativa de generalização, ambas defensáveis, ambas adequadas aos estudos de caso, ambas permitindo a acumulação do conhecimento.

Os critérios para avaliação de estudos de caso existem e são claramente expostos pelos autores aqui analisados. Embora haja divergências entre eles, parece haver acordo sobre o fato, amplamente aceito pela comunidade acadêmica, de que o estudo de caso qualitativo constitui uma investigação de uma unidade específica, situada em seu contexto, selecionada segundo critérios predeterminados e, utilizando múltiplas fontes de dados, que se propõe a oferecer uma visão holística do fenômeno estudado. Os critérios para identificação e seleção do caso, porém, bem como as formas de generalização propostas, variam segundo a vinculação paradigmática do pesquisador, a qual é de sua livre escolha e deve ser respeitada. $\bigcirc$ importante é que haja critérios explícitos para a seleção do caso e que este seja realmente um "caso", isto é, uma situação complexa e/ou intrigante, cuja relevância justifique o esforço de compreensão.

\section{REFERÊNCIAS BIBLIOGRÁFICAS}

ADORNO, W. Introdução à controvérsia sobre o positivismo na sociologia alemã. In: CIVITA, V. (coord.) Textos escolhidos. Benjamin, Horkheimer, Adorno e Habermas. São Paulo: Abril Cultural, 1983. p.209-257. (Col. Os Pensadores) 
ALVES-MAZZOTTI, A.J.; GEWANDSZNAJDER, F. O Método nas ciências naturais e sociais. pesquisa quantitativa e qualitativa. 2. ed. São Paulo: Pioneira, 2004.

BOGDAN, R.; BIKLEN, S. Investigação qualitativa em educação. Porto: Porto Editora, 1994. JACOBS, J. Morte e vida de grandes cidades. São Paulo: Martins Fontes, 2000.

KUHN, T. The Structure of scientific revolutions. Chicago: University of Chicago Press, 1970. MOROZ, M; GIANFALDONI, M. H. T. A. O Processo de pesquisa: iniciação. Brasília: Plano, 2002.

POPPER, K. R. Lógica das ciências sociais. Rio de Janeiro: Tempo Brasileiro, 1978.

STAKE. R. E. Case studies. In: DENZIN, N. K.; LINCOLN, Y. S. (ed.) Handbook of qualitative research. London: Sage, 2000. p. 435-454.

The Case study method in social inquiry. Educational Researcher, v.7, n.2, p.5-8, 1978.

YIN, R. K. Case study research: design and methods. London: Sage, 1984.

Recebido em: setembro 2005

Aprovado para publicação em: junho 2006 